\title{
APPLICATION OF THE ILKOVIČ EQUATION TO QUANTITATIVE POLAROGRAPHY
}

\author{
By Floyd Buckley and John Keenan Taylor
}

\section{ABSTRACT}

Conditions of applicability of the Ilkovič equation to polarographic analysis were investigated for representative ions singly and in mixtures. Gelatin was used to suppress maxima found in current-voltage curves.

Results obtained with a capillary of usual characteristics showed that a suppresser is necessary to secure agreement with the Ilkovič equation over any considerable drop-time range, and that the need increases with the drop-rate of the electrode and the dilution of reducible ion. A criterion of diffusion control satisfactory for classification of polarograms by visual examination was found. The application of the Ilkovič equation to quantitative analysis was shown to be inadvisable unless it is definitely established that the experimental conditions are well within the range for insuring diffusion control. A logarithmic relation between critical drop-time and suppresser concentration was found.

\section{CONTENTS}

Page

I. Introduction

II. Apparatus and method

III. Results _

IV. Conclusions _.

V. References_.......

\section{INTRODUCTION}

The polarographic method of chemical analysis is based upon the interpretation of the current-voltage curves obtained when solutions containing electroreducible or electrooxidizable substances are electrolyzed with electrodes, one of which is very small (usually mercury dropping from a fine-bore capillary) so that it is completely polarized, while the other is practically unpolarizable. From the position and magnitude of certain steps observed in these curves, both qualitative and quantitative information concerning the electrolyzed material can be obtained.

The polarograph, an instrument that automatically obtains and records these current-voltage curves, has numerous applications in chemical analysis. Most of the published procedures make use of the instrument as an interpolating device for comparing known and unknown solutions. If the standard and unknown solutions are sufficiently alike, and the same dropping electrode is employed for each under identical conditions, the analysis resolves into a comparison of the heights of the waves or steps on the current-voltage curves. 
The phenomenon of a limiting current which gives rise to the characteristic polarographic waves is determined, under ideal conditions, by the rate of diffusion of the electrolyzable ion from an inexhaustible supply in the surrounding solution to the surface of the electrode at which the concentration is zero because the ions are removed as rapidly as they arrive. The expression relating this diffusion current to the constants of the system under investigation was derived by Ilkovic $[1]^{1}$ in the form

$$
i_{d}=k n D^{1 / 2} \mathrm{Cm}^{2 / 3} t^{1 / 6},
$$

where $i_{d}$ is the diffusion current in microamperes, $n$ is the number of electron equivalents per mole of electrode reaction, $D$ is the diffusion coefficient of the reducible (or oxidizable) substance, $C$ is its concentration in millimoles per liter, $m$ is the mass flow of mercury from the dropping electrode in milligrams per second, $t$ is the drop-time in seconds, and $k$ is a proportionality constant. In this equation the quantity $k n D^{1 / 2}$ is a constant for the particular ion under investigation, whereas the other factor depends upon the concentration of the solution and the physical constants of the apparatus employed. Lingane [2] has accordingly proposed that the quantity $k n D^{1 / 2}$, which is experimentally determined by $i_{d} / \mathrm{Cm}^{2 / s} t^{1 / 6}$, be designated as the "diffusioncurrent constant." ${ }_{2}$ The use of this constant, together with the physical characteristics of the capillary and of the electrical system, would eliminate the need for calibration experiments and put polarography on an absolute basis.

The validity of the above procedure depends on strict agreement with the Ilkovič equation under the experimental conditions of the analysis. However, it is found that the polarographic waves are not determined by the diffusion current alone, but are often complicated by the presence of more or less pronounced maxima, caused by adsorption of the reducible ion on the mercury electrode, stirring of the electrolyte near the electrode, or other factors. Certain surfaceactive materials added to the electrolyte have been found to suppress these maxima. Although the Ilkovic equation has been tested by several investigators [3] and definite statements have been made as to the conditions for its validity, none of these researches has included a systematic study of the effect of suppressers of maxima on the diffusion current, but there are general statements in the literature which describe variations of wave height caused by the addition of a large excess of suppressing agents [4]. Indeed, no satisfactory criteria for determining when maxima have been suppressed and the electrode current is controlled by a simple diffusion process (hereafter referred to as diffusion control) have been proposed. Observations in this laboratory on the occurrence and nature of maxima have suggested the need of an exploratory investigation to determine the influence of the drop-rate of the capillary and the concentration of the suppresser on the validity of the fundamental Ilkovič equation. This information is necessary before Lingane's proposal can be generally applied to quantitative polarography.

\footnotetext{
1 Figures in brackets indicate the literature references at the end of this paper.

This diffusion-current constant differs from that previously employed by Kolthoff and Lingane (Chem. Rev. 24, 1 (1939) by the factor $m^{2 / 3} t^{1 / 6}$
} 


\section{APPARATUS AND METHOD}

The polarograph used was of the photographic recording type and has been described, together with its auxiliary equipment, in a previous communication from this laboratory [5]. The characteristics of the electrical measuring circuit were determined by the Electrical Division of this Bureau. In addition, the calibration of the galvanometer was checked by substituting a standard resistor for the dropping-electrode cell. Full-scale sensitivity of the galvanometer was $2.22 \times 10^{-9}$ ampere per millimeter at 1 meter. Nominal sensitivity ratios differed by no more than 1 percent from observed values.

The dropping electrode was constructed from a drawn-out capillary so that a maximum drop-time of about 6 seconds was obtained in the solutions under investigation. This capillary was sealed to a long burette of large cross section so that the driving head was not altered significantly during a 10-minute dropping interval. The burette was fitted with an enlarged funnel top and a stopcock sidearm near the bottom to facilitate adjustment of the driving head to obtain any desired drop-time in the range of 1 to 6 seconds.

The flow of mercury in the capillary was determined as a function of the driving head. The apparatus described by Lingane [6] was particularly suitable for this measurement. The flow is practically independent of the immersion medium (air, water, solution) but the drop-time is, of course, quite sensitive to the composition of the supporting electrolyte. A scale attached to the burette furnished a convenient means of ascertaining the driving head and hence the flow of mercury for each polarogram recorded. The drop-time of the capillary was taken by means of a stopwatch at the half-wave potential of the particular ion under investigation.

Galvanometer sensitivities were selected to produce wave heights of such size that errors in their measurement were reduced to about 1 percent, except for the solutions of extreme dilution, in which case the errors were no more than two or three times this amount.

Characteristic types of polarograms encountered in this investigation and the usual methods of measuring wave heights are shown in figure 1. The segment preceding the wave is extended, as shown in the figure, to compensate for rise in residual current. The method for estimating the current at the completion of a wave depends upon the shape of the wave and the slope of the following segment. In the absence of prominent maxima, three types of waves are observed. The slope of the following segment may be equal to, as in $A$, less than, as in $B$, or greater than, as in $C$, that of the initial segment. In cases $A$ and $B$, a line is drawn parallel to the initial portion of the wave and through the maximum of the final portion. Case $C$ permits the backward extension of the following segment. In each case the wave height is taken as the vertical distance at the half-wave potential. When sharp maxima are present as in $D$ and $E$, the peak is ignored and estimation of wave height is made as in $A$ and $B$.

The above-described methods of measuring wave heights are frequently used and are satisfactory for comparative purposes, but it is later shown that they do not provide true measures of diffusion currents except when the form of the polarographic wave is like that 
shown in figure $1, A$, as this is the only type of wave obtained when the electrode current is determined by a simple diffusion process. This fact forms the basis of a criterion for the minimum concentration of suppresser necessary to insure diffusion control of the electrode current.

Nickel, cadmium, bismuth, and thallium were selected as the cations for study. This group provided a bivalent ion (Cd) having a half-wave potential very near that of the electrocapillary maximum, one bivalent $(\mathrm{Ni})$ and one univalent ion $(\mathrm{Tl})$ reduced at potentials on either side of the electrocapillary maximum, and one trivalent ion (Bi). The selection is a reasonable cross section of the type of cation encountered in elementary analysis. The supporting electrolyte was $0.1 N$ in potassium chloride for nickel, cadmium, and thallium and $1 N$ in nitric acid for bismuth.

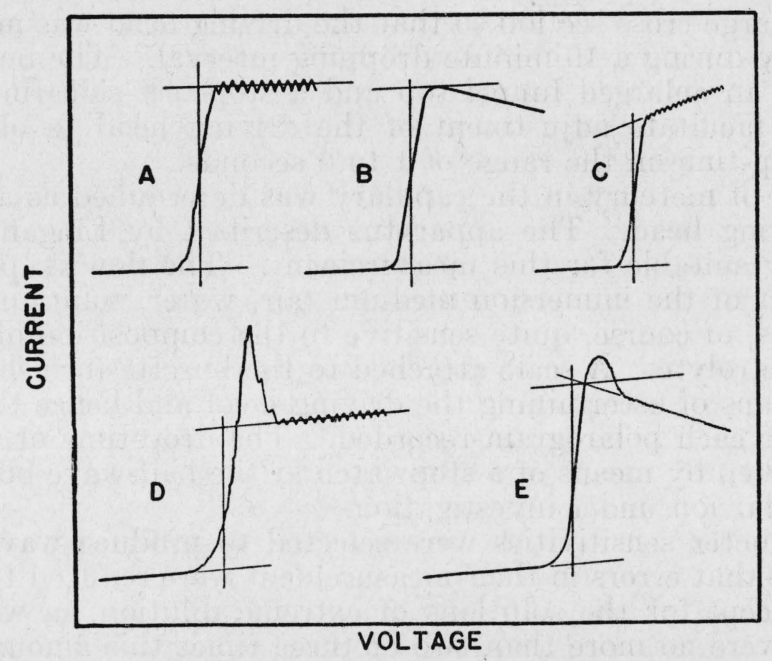

FIgURE 1.-Methods of measurement for characteristic types of polarographic waves.

Solutions of nickel, cadmium, and bismuth were prepared by quantitative dilution of standards made from spectrochemically pure metals. The thallium standard was prepared from pure TlCl.

Polarograms for each solution were taken over a drop-time range of 1 - to 6 -second intervals of approximately 0.5 second for nickel and cadmium and approximately 1 second for thallium and bismuth. The gelatin concentration was increased in increments of 0.002 percent in all cases except for cadmium. The range of gelatin concentration was 0 to 0.008 percent for cadmium, thallium, and bismuth and 0 to 0.020 percent for nickel.

Oxygen was removed by bubbling purified nitrogen through the solution in the cell for 15 minutes preceding the recording of the polarogram, and its reentrance was prevented by a continuous flow of nitrogen over the solution during the measurement.

All measurements were made in a constant-temperature room maintained at $25.5^{\circ} \pm 0.3^{\circ} \mathrm{C}$. 


\section{RESULTS}

Values of the diffusion-current constant $I_{D}=i_{d} / \mathrm{Cm}^{2 / 3} t^{1 / 6}$ were calculated from the measured wave heights and the characteristics of the apparatus and electrode. The results for various solutions of nickel as a function of drop-time of the electrode and gelatin concentration are given in figure 2. The failure to comply with the law expressed by the equation for $I_{D}$ is strikingly evident in the absence of a suppresser in that no constant value of $I_{D}$ over an appreciable range of drop-times is observed. With the small gelatin content of 0.002 percent, however, constant values of $I_{D}$ are obtained for all drop-times greater than 3 seconds. At a concentration of 0.004 percent of gelatin the critical drop-time is decreased to 2.1 seconds and at 0.006 percent to 1.8 seconds. Solutions containing between 0.008 and 0.020 percent of gelatin give, for fixed gelatin concentrations, constant values of $I_{D}$ over the entire drop-time range of 1 to 6 seconds. ${ }^{3}$

A representative selection of the polarograms obtained for a solution $0.142 \times 10^{-3} M$ in nickel is shown in figure $3 .^{4}$ For all the polarograms in horizontal alinement, the gelatin content was that indicated at the right side of the figure, and for all those in vertical alinement the drop-time did not differ by more than 0.1 second from the nominal value listed at the top of the figure. Values calculated for the diffusion-current constant are inserted at the base of each polarogram. At first inspection, all the curves with the exception of the last two on the right at 0 percent and the last one on the right at 0.002 percent of gelatin appear regular and "well defined." A study of the figure reveals the danger of gross error incurred from the assumption of diffusion control as determined by the loose criterion of "good definition." A positive criterion that has been found to be sufficient in this and all other cases of this study is the near identity of slope at the beginning and end of a wave.

The effect of gelatin, at least for concentrations less than 0.02 percent, in diminishing the diffusion-current constant, was found to be significant only at high dilution of the reducible ion. The family of curves shown in figure 4 illustrates the magnitude of this effect in solutions of nickel. These curves show that diffusion control exists over the entire drop-time range of 1 to 6 seconds for a concentration of gelatin in the neighborhood of 0.006 percent. An increase in suppresser concentration to 0.014 percent $(0.020$ percent for solutions $0.568 \times 10^{-3} M$ and $0.0284 \times 10^{-3} M$ ) gives no further change in $I_{D}$ for the two higher concentrations of nickel but causes a small continuous decrease at the higher dilutions. The effect is most pronounced at the lowest concentration of nickel.

The results depicted in figure 4 offer an explanation of conflicting statements which have been made regarding the strict proportionality of concentration of the reducible ion and its diffusion current. The curves show that this proportionality depends both upon drop-time

\footnotetext{
${ }^{3}$ For a given gelatin content, a slight increase in the values for $I_{D}$ at the higher drop-times is noted, especially for the lowest concentrations of the reducible ion. The magnitude of this increase is small and of the order of the experimental errors involved in its determination. It may be due to some systematic error introduced by the method of measurement of the wave heights. However, the errors incurred on the assumption of a constant value for $I_{D}$, when diffusion control is effective, should not exceed \pm 2 percent.

The conclusions of this paper are based upon the interpretation of approximately 800 current-voltage curves, which obviously can not be published in entirety. The polarograms shown have been selected because they illustrate characteristic behavior.
} 


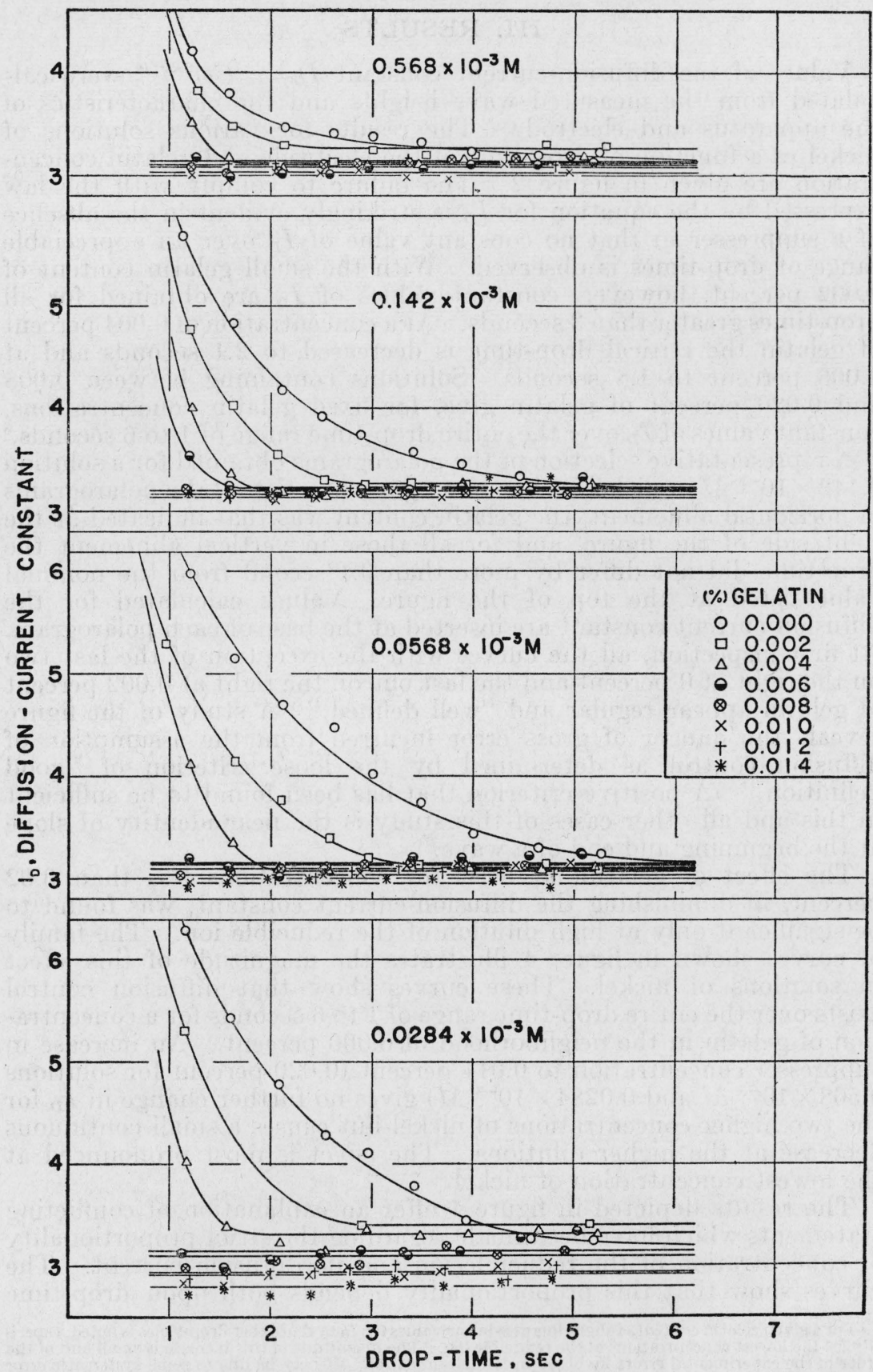

FIGURE 2.-Effect of gelatin and drop-time on the diffusion-current constant of nickel in a supporting electrolyte of $0.1 \mathrm{~N} \mathrm{KCl}$. 
and gelatin content. Thus constant values of $I_{D}$ are obtained over the entire drop-time range of 1 to 6 seconds only if the gelatin concentration is very near 0.006 percent. At lower gelatin content the proportionality is valid only in a very restricted drop-time range. At high gelatin concentrations, proportionality exists only if the ion concentration is in the vicinity of $0.1 \times 10^{-3} M$ or higher.

The behavior of cadmium is of special interest as this element is reduced at a potential very close to the electrocapillary maximum. Both the adsorption theory of Heyrovsky [7] and Ilkovic [8], and the electrostatic streaming theory of Antweiler [9] demand that, at this potential, maxima be either absent or of small magnitude. Hence, deviations from the Ilkovič equation might be expected to be very small for this element. Indeed, positive assertions that cadmium shows no maximum in a $0.1-N$ solution of potassium chloride have been made [10].

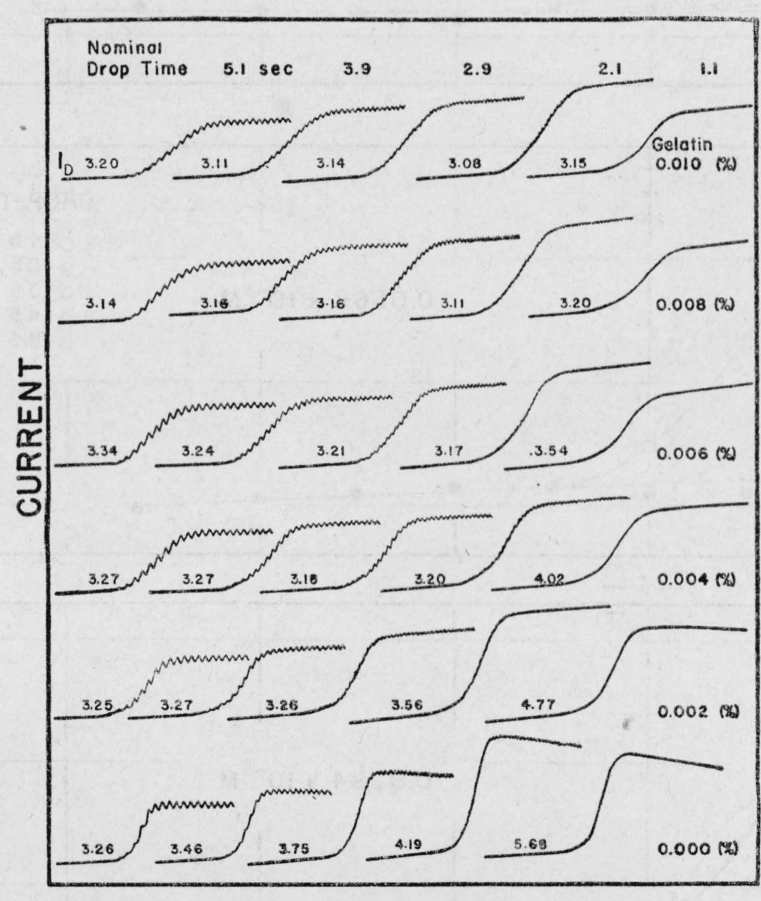

VOLTAGE

FIGURE 3.-Characteristic polarographic waves for nickel $\left(0.142 \times 10^{-3} \mathrm{M}\right)$ in a supporting electrolyte of $0.1 \mathrm{~N} \mathrm{KCl}$.

All polarograms were taken at a sensitivity of $1 / 20$, except those at a nominal drop-time of 1.1 seconds, which were taken at $1 / 40$.

Figures 5 and 6 show the results for a solution $0.0148 \times 10^{-3} M$ in cadmium. The general behavior is similar to that of nickel. Gelatin is required to secure agreement with the Ilkovič equation and deviations at high drop-rates in the presence of insufficient suppresser are shown by the appearance of a decreased slope at the end 
104 Journal of Research of the National Bureau of Standards

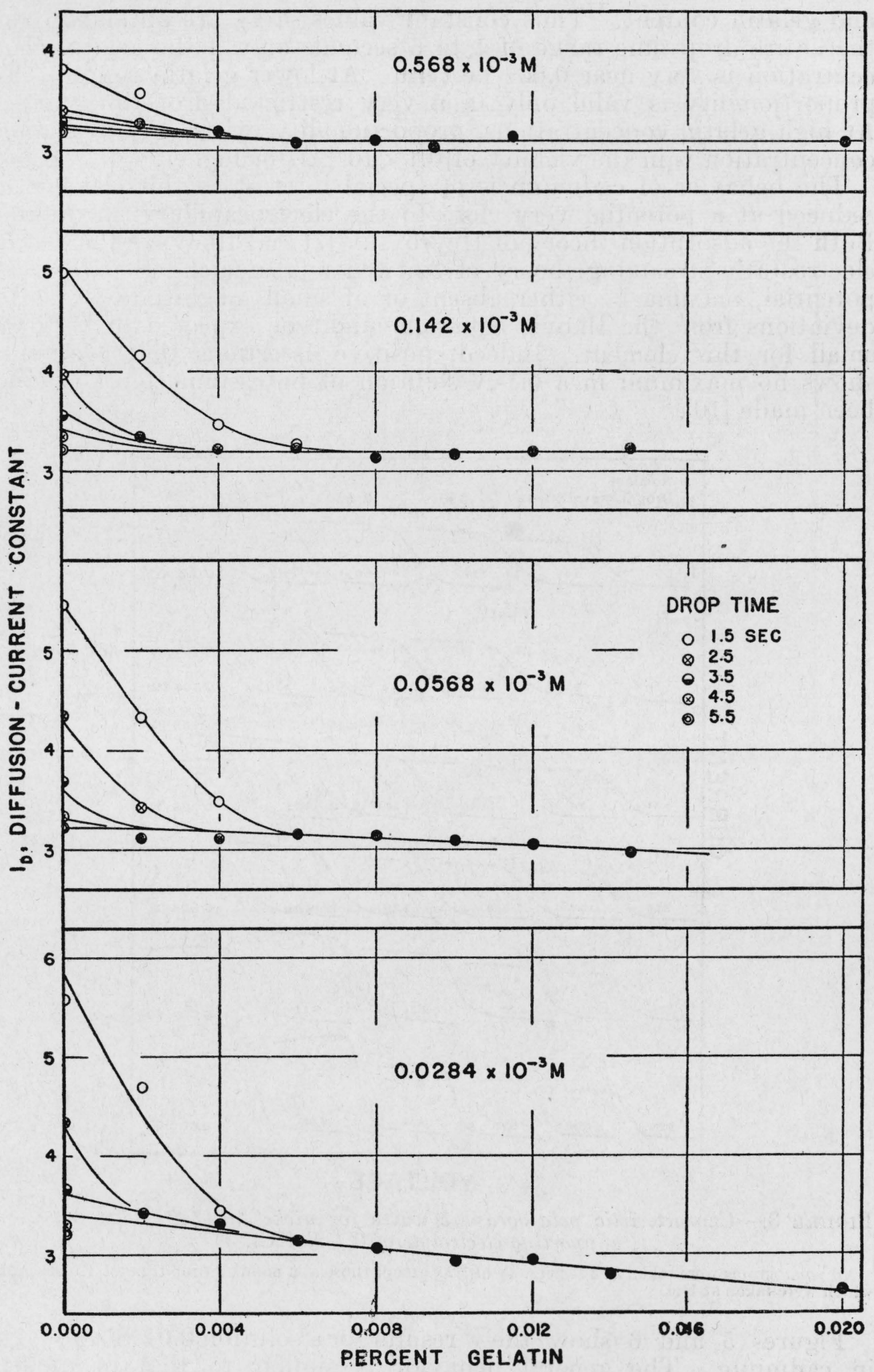

FIgURE 4.-Effect of gelatin on the diffusion-current constant of nickel for specific. drop-times in a supporting electrolyte of $0.1 \mathrm{~N} \mathrm{KCl}$.

The symbol denotes the superposition of points corresponding to the different drop-times. 
of the wave (figure 6). Sharp maxima are absent and all waves are "well defined." The writers' conclusion that the appearance of welldefined waves is not sufficient evidence for diffusion control is confirmed. The positive criterion found to be valid for nickel, that is, the approximate equality of the slopes preceding and succeeding the wave, was also applicable to all cadmium solutions.

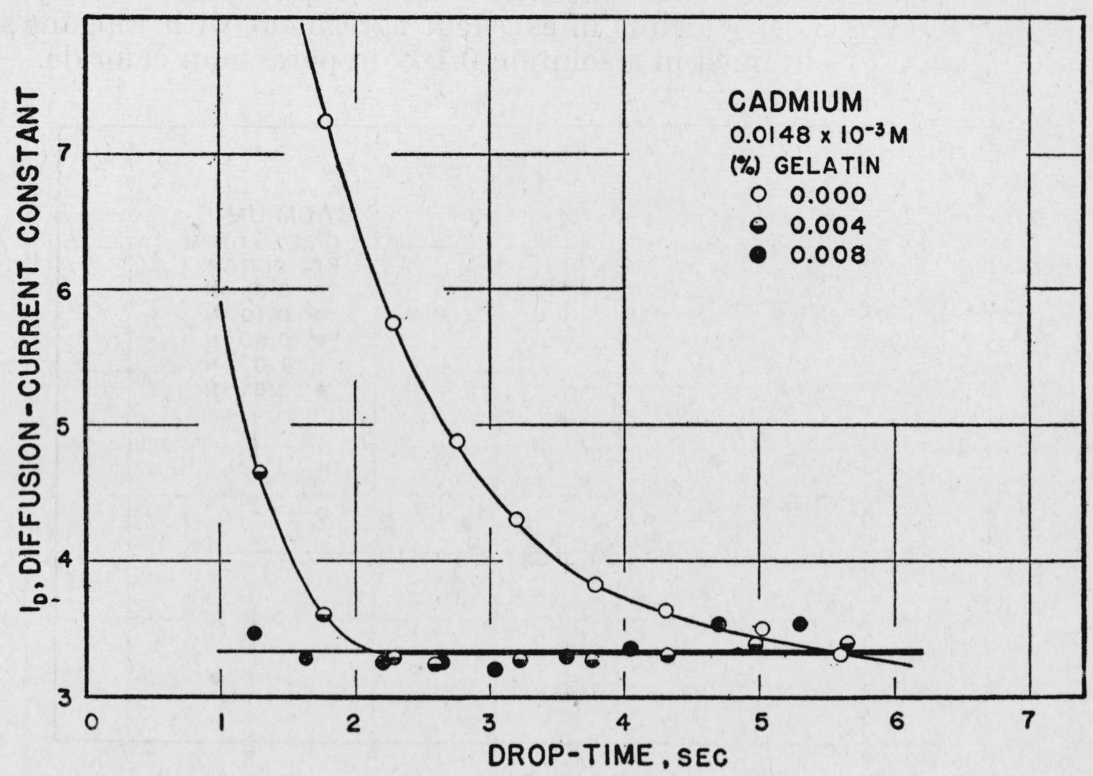

FIGURE 5.-Effect of gelatin and drop-time on the diffusion-current constant for cadmium in a supporting electrolyte of $0.1 \mathrm{~N} \mathrm{KCl}$.

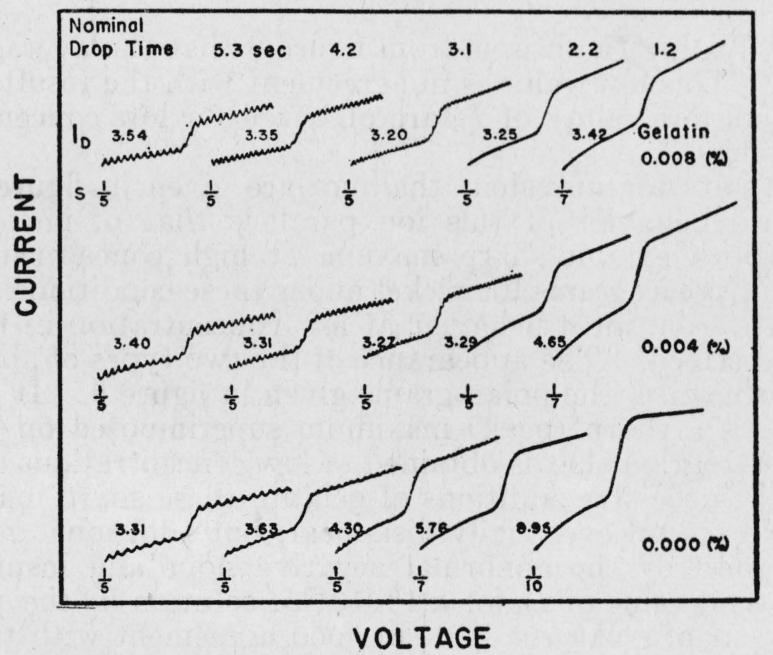

FIGURE 6.-Characteristic polarographic waves of cadmium $\left(0.0148 \times 10^{-3} \mathrm{M}\right)$ in a supporting electrolyte of $0.1 \mathrm{~N} \mathrm{KCl}$.

The fractions under the curves!denote sensitivities. 
The deviations shown by cadmium when electrolyzed from solutions of potassium chloride of various concentrations and in the absence of gelatin are shown in figure 7. All polarograms are regular, "well defined," and show the characteristic appearance of a decreased slope at the end of the wave for drop-times less than 3 seconds. Constant values of $I_{D}$ are obtained only for drop-times greater than 3 seconds. The value of $I_{D}$ found with concentrations of supporting electrolyte less than $1 N$ is 3.54, which is in excellent agreement with Lingane's value [2] of 3.51 obtained in a solution $0.1 \mathrm{~N}$ in potassium chloride.

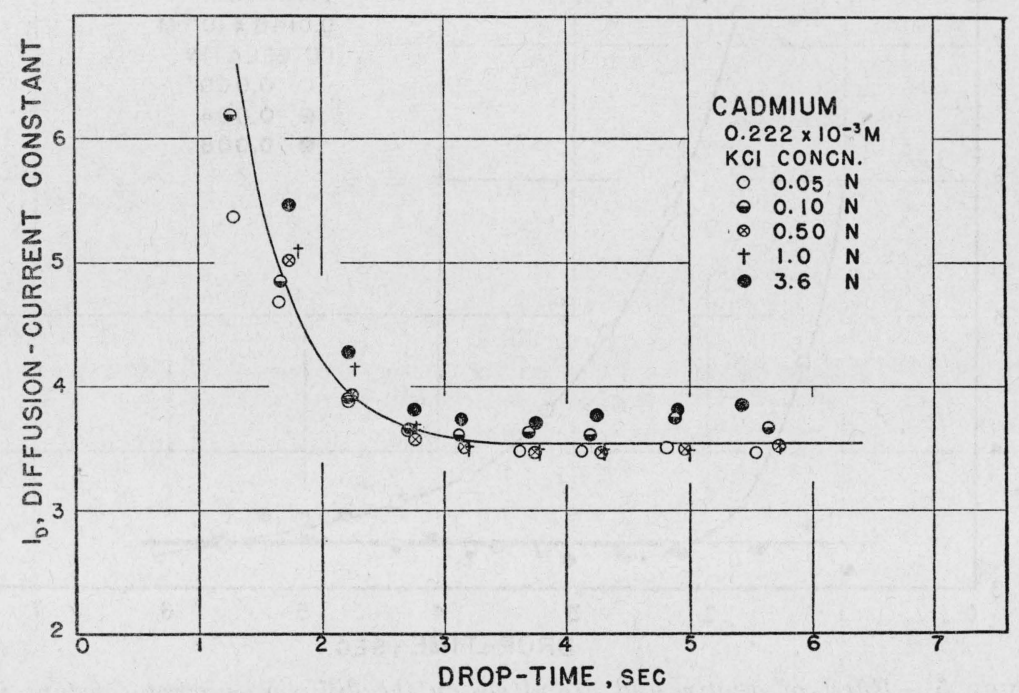

FIGURE 7.-Influence of drop-time and concentration of supporting electrolyte on the diffusion-current constant of cadmium in solutions of potassium chloride.

It is interesting to observe from figure 6 that the average value of $I_{D}$ is 3.35. This low value is in agreement with the results found for nickel where low values of $I_{D}$ are observed for low concentrations of reducible ion.

Some results for univalent thallium are given in figures 8 and 9 . The general behavior of this ion parallels that of nickel in every respect. Both exhibit sharp maxima at high concentrations of reducible ion (polarograms for nickel under these conditions not shown) and deviate from ideal behavior at low concentration in the manner already described. The appearance of the two types of abnormalities is clearly shown in the polarograms given in figure 9. It is observed that there is a sharp (peak) maximum superimposed on the regular type of polarogram that is obtained at low concentrations of reducible ion. With successive additions of gelatin, these sharp maxima gradually decrease and eventually disappear, but additional gelatin is required to destroy the abnormal negative slope and insure diffusion control. The value of $I_{D}$ for a $1 \times 10^{-3} M$ solution in the presence of 0.008 percent of gelatin is 2.71 , in good agreement with the value of 2.69 reported by Lingane and Kolthoff [3]. The decrease of $I_{D}$ with extreme dilution of reducible ion previously observed for nickel and cadmium is confirmed in the present instance. 


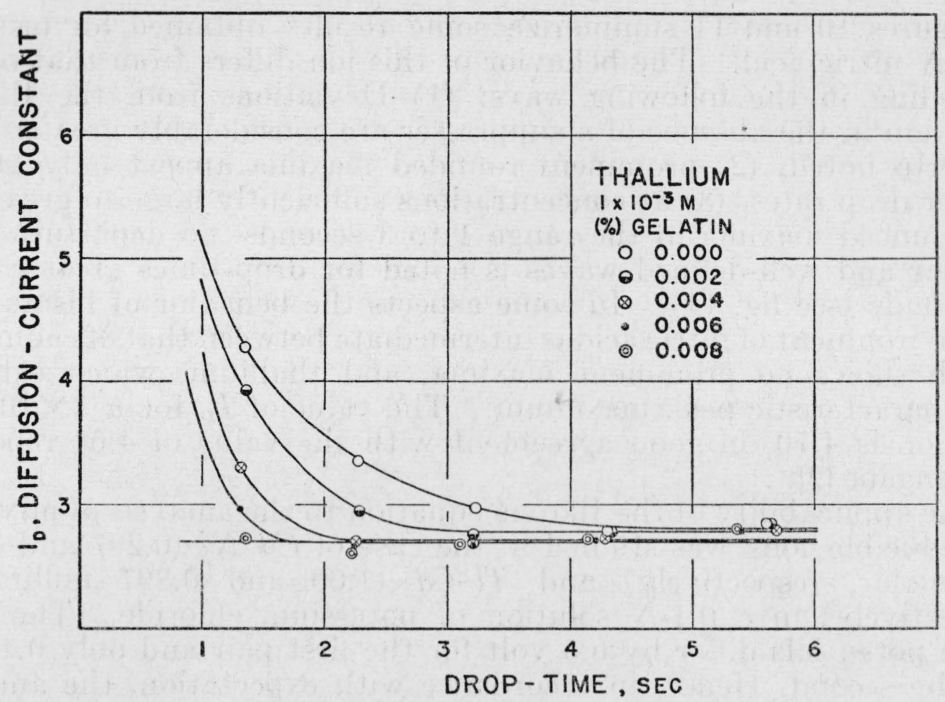

FIGURE 8.-Effect of gelatin and drop-time on the diffusion-current constant of thallium in a supporting electrolyte of $0.1 \mathrm{~N} \mathrm{KCl}$.

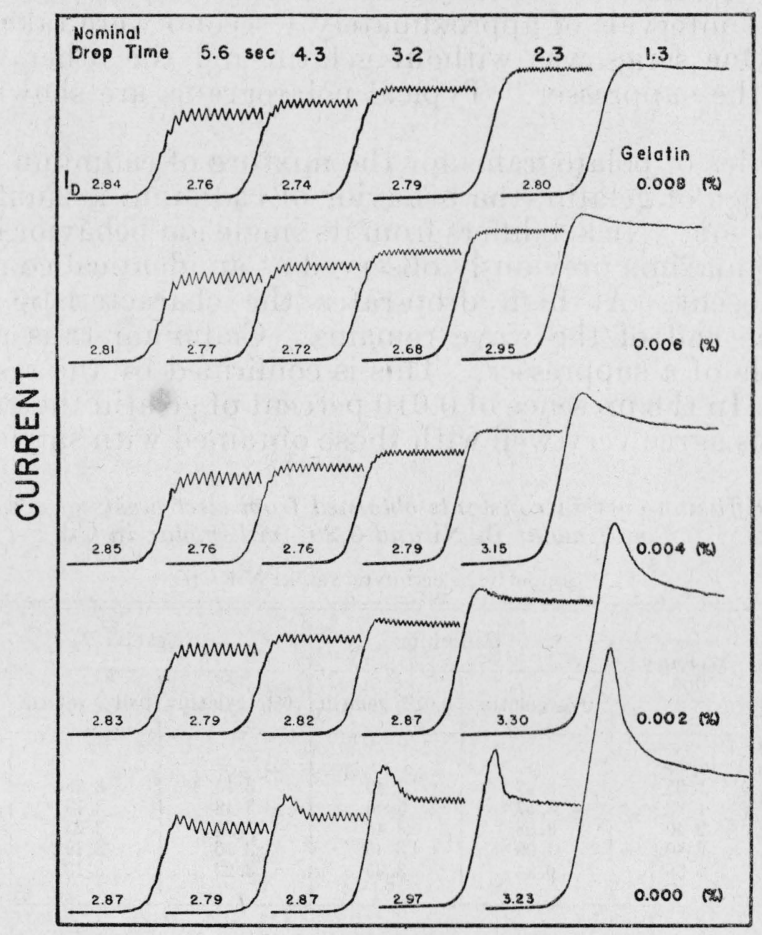

\section{VOLTAGE}

FIGURE 9.-Characteristic polarographic waves of thallium $\left(2 \times 10^{-3} \mathrm{M}\right)$ in a supporting electrolyte of $0.1 \mathrm{~N} \mathrm{KCl}$.

All polarograms were taken at a sensitivity of $1 / 150$, except those at a nominal drop-time of 1.3 seconds for 0.000 and 0.002 percent of gelatin and for 2.3 seconds at 0.000 percent of gelatin, which were taken at a sensitivity of $1 / 200$. 
Figures 10 and 11 summarize some results obtained for bismuth in $1 \mathrm{~N}$ nitric acid. The behavior of this ion differs from that of the preceding in the following ways: (1) Deviations from the Ilkovič equation in the absence of a suppresser are considerably greater than hitherto noted, (2) prominent rounded maxima appear only at the higher drop rates, (3) at concentrations sufficiently large to give very pronounced maxima in the range 1 to 3 seconds, no departure from regular and well-defined waves is noted for drop-times greater than 4 seconds (see fig. 11). In some aspects the behavior of bismuth in an environment of nitric acid is intermediate between that of cadmium, which shows no prominent maxima, and thallium, which exhibits the characteristic peak maximum. The value of $I_{D}$ for a $1 \times 10^{-3} \mathrm{M}$ solution is 4.70 , in good agreement with the value of 4.64 reported by Lingane [2].

The applicability of the Ilkovič equation to the analysis of mixtures of reducible ions was studied in the case of $C d-N i$ (0.297 and 0.568 millimolar, respectively) and $T l-C d(1.00$ and 0.897 millimolar, respectively) in a $0.1-N$ solution of potassium chloride. The halfwave potentials differ by 0.5 volt for the first pair and only 0.1 volt for the second. Hence, in accordance with expectation, the analysis of the $C d-N i$ mixture was very satisfactory and that of $T l-C d$ quite uncertain. Two series of polarograms over a drop-time range of 1 to 6 seconds at intervals of approximately 1 second were taken for each mixture. One series was without gelatin and the other with 0.010 percent of the suppresser. Typical polarograms are shown in figure 12.

In the series of polarograms for the mixture of cadmium and nickel in the absence of gelatin, the behavior of cadmium is similar to that of the single ion. Nickel differs from its single ion behavior in that the small sharp maxima previously observed at an identical concentration are now absent. At high drop-rates the characteristic decreased slope at the end of the wave remains. Cadmium thus appears to play the role of a suppresser. This is confirmed by the results given in table 1. In the presence of 0.010 percent of gelatin the values of $I_{D}$ for both ions agree very well with those obtained with single ions.

TABLE 1.-Diffusion-current constants obtained from electrolysis of a solution 0.568 millimolar in $\mathrm{Ni}$ and 0.297 millimolar in $\mathrm{Cd}$

[Supporting electrolyte was $0.1 \mathrm{~N} \mathrm{KCl]}$

\begin{tabular}{|c|c|c|c|c|}
\hline \multirow{2}{*}{$\begin{array}{c}\text { Mercury } \\
\text { flow }\end{array}$} & \multicolumn{2}{|c|}{ Cadmium } & \multicolumn{2}{|c|}{ Nickel } \\
\cline { 2 - 5 } \cline { 4 - 5 } & $0 \%$ gelatin & $0.01 \%$ gelatin & $0 \%$ gelatin & $0.01 \%$ gelatin \\
\hline & & & & \\
\hline$m g / s e c$ & & 3.49 & 3.15 & 3.18 \\
1.35 & 3.47 & 3.46 & 3.18 & 3.19 \\
1.79 & 3.57 & 3.46 & 3.20 & 3.23 \\
2.40 & 3.58 & 3.40 & 3.16 & 3.19 \\
3.40 & 4.09 & 3.35 & 3.22 & 3.12 \\
5.80 & 6.24 & & & \\
\hline
\end{tabular}

The mixture of cadmium and thallium is of particular interest because of the information it yields regarding the general resolving power of the method of analysis. In the polarograms for this mixture without gelatin, the thallium wave is regular and well defined over the entire drop-time range. The deposition of cadmium immediately 


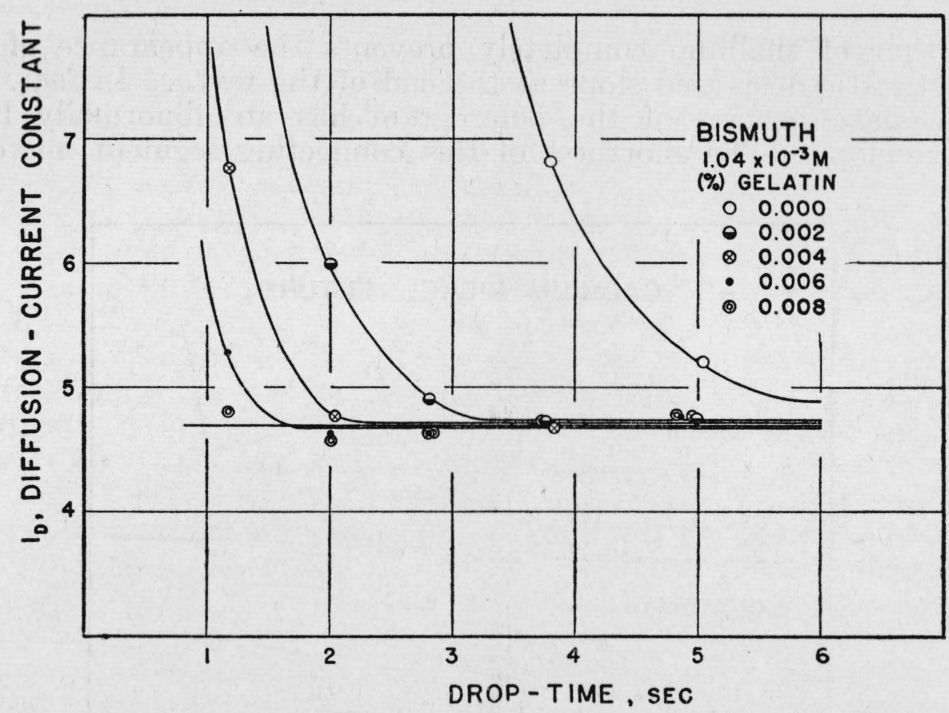

FIGURE 10.-Effect of gelatin and drop-time on the diffusion-current constant of bismuth in a supporting electrolyte of $1 \mathrm{~N}^{-} \mathrm{NO}_{3}$.

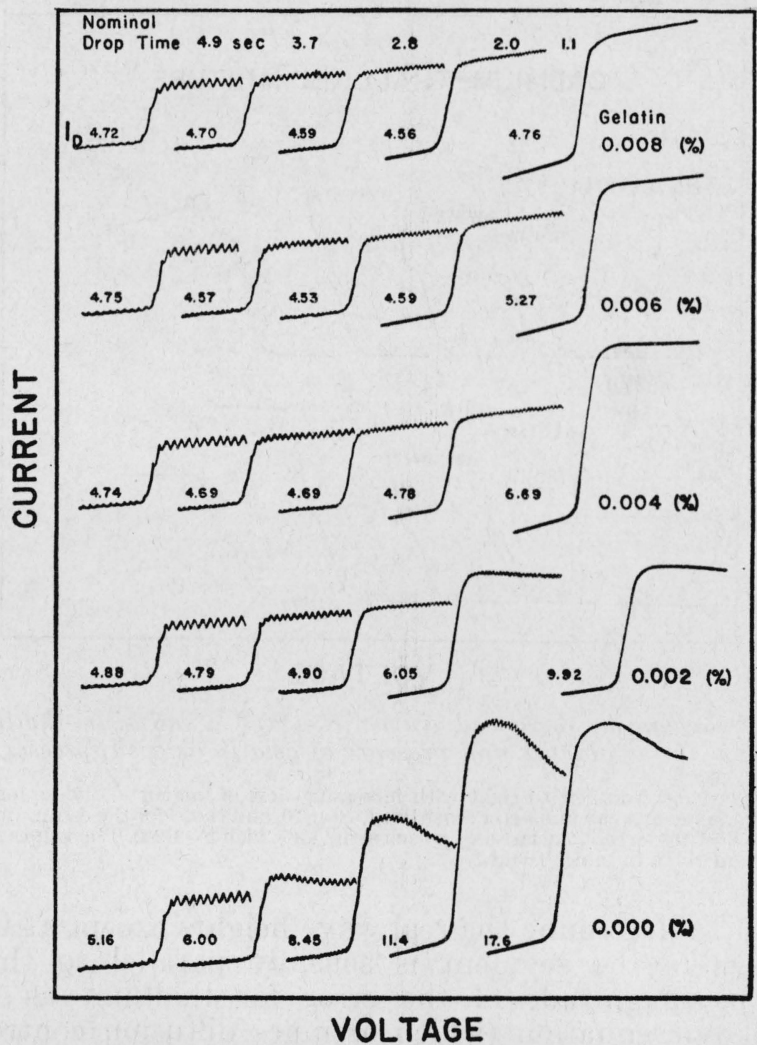

FIGURE 11.-Characteristic polarographic waves for bismuth $\left(0.104 \times 10^{-3} \mathrm{M}\right)$ in a supporting electrolyte of $1 \mathrm{~N} \mathrm{HNO}_{3}$.

All polarograms were taken at a sensitivity of $1 / 20$, except those at a nominal drop-time of 1.1 seconds for .000 percent and 0.002 percent of gelatin, which were taken at a sensitivity of $1 / 40$. 
after that of thallium completely prevents the appearance of the characteristic decreased slope at the end of the wave. In fact, this intermediate portion of the polarogram has an abnormally large positive slope. The shortness of this connecting segment makes it

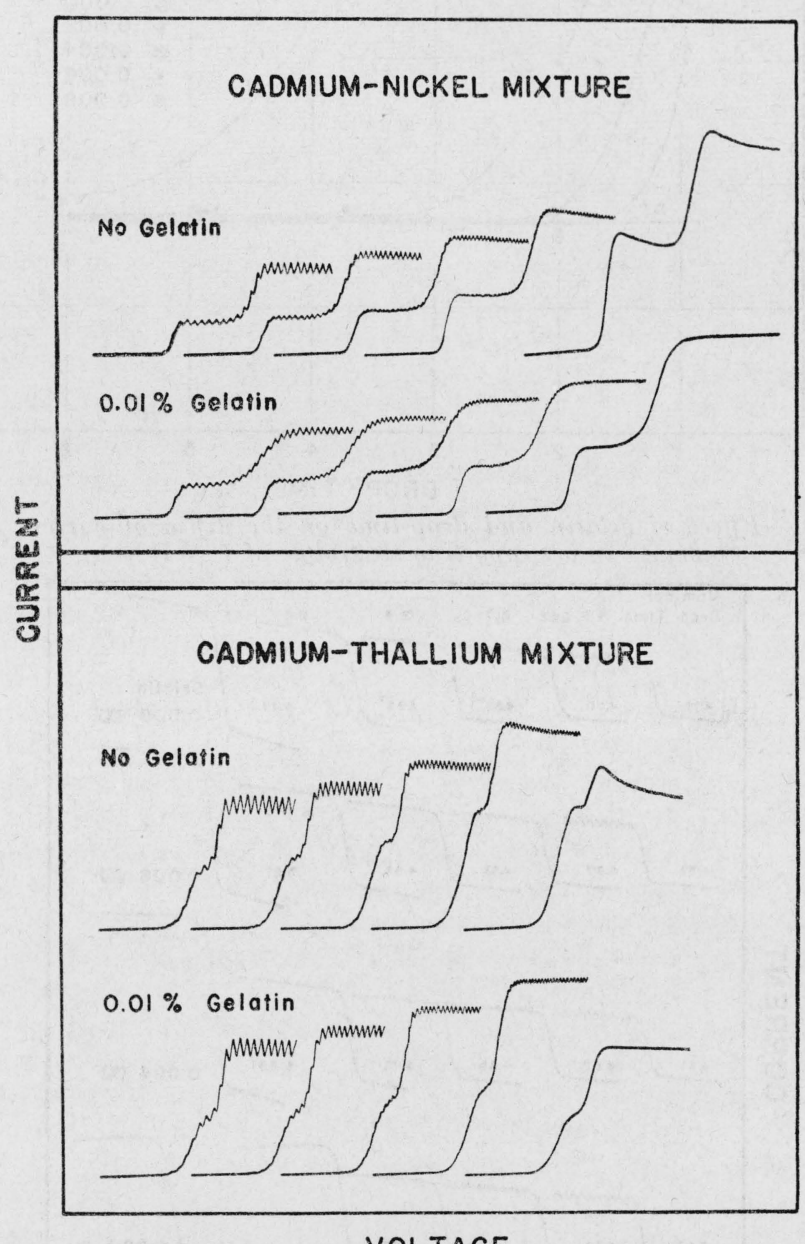

FIgURE 12.-Polarograms for a cadmium-nickel and a cadmium-thallium mixture taken in the absence and presence of gelatin as a suppresser.

Polarograms are ordered from left to right with increasing flow of mercury. Those for the cadmiumnickel mixture were taken at a galvanometer sensitivity, $S=1 / 70$, and those for the cadmium-thallium mix. ture were taken at $S=1 / 100$, except the last one in each series for which $S=1 / 200$. The values for $I_{D}$ calculated from these curves are given in tables 1 and 2.

very difficult to determine the real wave heights except at the highest drop-rate, where the segment is sensibly parallel to the residual current. The magnitude of the error for thallium as calculated from the Ilkovič equation (which assumes diffusion control) can be seen from table 2 . 
TABLE 2.-Diffusion-current constants obtained from electrolysis of a solution 1.0 by $10^{-3} \mathrm{M}$ in thallium and 0.897 by $10^{-3} \mathrm{M}$ in cadmium

[Supporting electrolyte was $0.1 \mathrm{~N} \mathrm{KCl}$.]

\begin{tabular}{|c|c|c|c|c|}
\hline \multirow{2}{*}{$\begin{array}{l}\text { Mercury } \\
\text { flow }\end{array}$} & \multicolumn{2}{|c|}{ Cadmium } & \multicolumn{2}{|c|}{ Thallium } \\
\hline & $0 \%$ gelatin & $0.01 \%$ gelatin & $0 \%$ gelatin & $0.01 \%$ gelatin \\
\hline $\begin{array}{c}m g / s e c \\
1.35 \\
1.75 \\
2.40 \\
3.40 \\
5.80\end{array}$ & $\begin{array}{l}3.50 \\
3.17 \\
3.14 \\
2.93 \\
2.09\end{array}$ & $\begin{array}{l}3.95 \\
3.81 \\
3.73 \\
3.63 \\
3.57\end{array}$ & $\begin{array}{l}2.82 \\
2.97 \\
3.13 \\
3.53 \\
5.54\end{array}$ & $\begin{array}{l}2.53 \\
2.51 \\
2.51 \\
2.50 \\
2.65\end{array}$ \\
\hline
\end{tabular}

In this mixture the cadmium wave has the form observed when the ion is alone. However, the series is very abnormal in that the diffusion current for this ion at high drop-rates is much too small. The reason for this is that the total current at the end of the cadmium wave is chiefly limited by the total normal diffusion current of both ions, and therefore thallium, which is characterized by a prominent maximum and is reduced first, assumes a disproportionately large share of the total current. The polarograms clearly show that the fractional reduction of the total current in the presence of 0.010 percent of gelatin is very much less than that for thallium alone. In the presence of a suppresser the cadmium wave becomes normal, and the form of the thallium wave remains unchanged. The difficulty of determining the end of the thallium wave and the beginning of the cadmium wave can be seen from the fact that the values of $I_{D}$ for thallium are too low and those for cadmium too high. This reflects the difficulty of determining wave-height when the segment connecting two waves is very short and of abnormal slope.

The three types of maxima encountered in this study are illustrated in figures 6,9 , and 11 . The sharp maxima characteristic of univalent thallium and nickel (polarograms not shown) and the particularly simple departure from normal behavior exhibited by cadmium (fig. 6) can be taken as extreme types. The rounded maxima appearing at intermediate and high drop-rates in the case of bismuth (fig. 11) can be regarded as a transition type. The change caused in these polarograms by the addition of successive increments of gelatin is instructive. Whereas relatively large concentrations of gelatin are required to suppress maxima of the cadmium type, only small amounts of suppresser are necessary to eliminate sharp or rounded peaks. The resulting polarographic waves, however, show departure from ideal behavior like those of cadmium and exhibit the same response to further additions of suppresser. It is also noted that for the lowest drop-time and at intermediate concentrations of gelatin the waves for thallium appear to be the resultant of a small peak maximum superimposed upon a curve of the cadmium type. At low concentrations of reducible ion (see, for example, fig. 3) only the cadmium type of maximum is found. These observations suggest that sharp maxima may be primarily caused by adsorption and those of the more general and persistent cadmium type chiefly by streaming phenomena.

The appearance of a reduced slope for that segment following the polarographic wave is not caused by a decrease in the value of the $627528-45-2$ 
factor $m^{2 / 3} t^{1 / 6}$ with increase in applied potential. The results of this study show this quantity is independent of gelatin concentrations as high as 0.012 percent and decreases by only 2.0 percent in the range of voltage from cadmium to nickel. This confirms the earlier work of Lingane and Kolthoff [3] who found a 2.2-percent decrease from -0.5 to -1.1 volts. It is therefore incorrect to attribute the large decrease in slope so frequently observed to the operation of this factor. Greater deviations from parallelism of initial and final portions of a wave must be attributed to lack of diffusion control of the electrode process.

Although there is conclusive evidence of a real deviation from the Ilkovic equation for conditions under which it is generally assumed to be applicable, there might be the objection that the bulk of the discrepancies observed in this investigation are in reality caused by a peculiarity of the dropping electrode. However, if the mass of the drop delivered by a capillary (practically constant over a wide range of flow, gelatin content, and voltage) is considered a satisfactory capillary characteristic, a drop of $7.7 \mathrm{mg}$ mass delivered by the electrode used in this study is well within the range 6 to $9 \mathrm{mg}$ of several electrodes reported in the literature [11]. Moreover, experiments with a special capillary delivering drops of $40.7 \mathrm{mg}$ show the same type of deviations. It was observed, however, that conditions of drop-time, concentration of reducible ion, and gelatin content under which departure from ideality occur were noticeably different.

An examination of all families of curves similar to figure 2 reveals the singular fact that for a fixed gelatin content the critical drop-time at which diffusion control ceases is (within experimental error) independent of the nature of the reducible ion, its concentration, and the supporting electrolyte. This fact suggests that for the simple metal cations diffusion control is primarily determined by characteristics of the dropping electrode and the nature and concentration of the suppressor. Table 3 summarizes the data obtained in this investigation, and figure 13 is the corresponding logarithmic plot for the individual ions.

The results shown in figure 13 are in accord with the simple adsorption theory for the suppression of maxima. ${ }^{5}$ From a consideration

TABLE 3.-Critical drop-times for various reducible ions in the presence of gelatin

\begin{tabular}{|c|c|c|c|c|c|c|c|c|c|c|c|}
\hline \multicolumn{3}{|c|}{ Nickel } & \multicolumn{3}{|c|}{ Cadmium } & \multicolumn{3}{|c|}{ Thallium } & \multicolumn{3}{|c|}{ Bismuth } \\
\hline $\begin{array}{c}\text { Concentra- } \\
\text { tion }\end{array}$ & Gelatin & $\begin{array}{l}\text { Critical } \\
\text { drop- } \\
\text { time }\end{array}$ & $\begin{array}{l}\text { Con- } \\
\text { centra- } \\
\text { tion }\end{array}$ & Gelatin & $\begin{array}{l}\text { Critical } \\
\text { drop- } \\
\text { time }\end{array}$ & $\begin{array}{l}\text { Con- } \\
\text { centra- } \\
\text { tion }\end{array}$ & Gelatin & $\begin{array}{c}\text { Critical } \\
\text { drop- } \\
\text { time }\end{array}$ & $\begin{array}{l}\text { Con- } \\
\text { centra- } \\
\text { tion }\end{array}$ & Gelatin & $\begin{array}{l}\text { Critical } \\
\text { drop- } \\
\text { time }\end{array}$ \\
\hline $\begin{array}{r}\text { Millimolar } \\
0.0284\end{array}$ & $\begin{array}{l}\text { Per- } \\
\text { cent } \\
0.002 \\
.004 \\
.006\end{array}$ & $\begin{array}{c}\text { Seconds } \\
2.90 \\
1.80\end{array}$ & $\begin{array}{c}\text { Milli- } \\
\text { molar } \\
0.00593\end{array}$ & $\begin{array}{c}\begin{array}{l}\text { Per- } \\
\text { cent }\end{array} \\
0.004\end{array}$ & $\begin{array}{r}\text { Seconds } \\
2.20\end{array}$ & $\begin{array}{c}\begin{array}{c}\text { Milli- } \\
\text { molar } \\
0.05\end{array} \\
0.05 \\
\end{array}$ & $\begin{array}{c}\text { Per- } \\
\text { cent } \\
0.002 \\
.004 \\
.006\end{array}$ & $\mid \begin{array}{r}\text { Seconds } \\
2.90 \\
2.20\end{array}$ & \begin{tabular}{c} 
Milli- \\
molar \\
0.0311 \\
\hdashline
\end{tabular} & $\begin{array}{c}\text { Per- } \\
\text { cent } \\
0.002 \\
.004 \\
.006\end{array}$ & $\begin{array}{r}\text { Seconds } \\
2.6 \\
1.9 \\
\end{array}$ \\
\hline .0568 & $\left\{\begin{array}{l}.002 \\
.004 \\
.006\end{array}\right.$ & $\begin{array}{l}3.70 \\
2.10\end{array}$ & .0148 & .004 & 2.30 & .10 & $\begin{array}{l}.002 \\
.004 \\
.006\end{array}$ & $\begin{array}{l}2.80 \\
2.20 \\
1.80\end{array}$ & \begin{tabular}{|r}
.104 \\
\hdashline
\end{tabular} & $\begin{array}{l}.002 \\
.004 \\
.006\end{array}$ & $\begin{array}{l}3.1 \\
2.3 \\
1.8\end{array}$ \\
\hline .142 & $\left\{\begin{array}{l}.002 \\
.004 \\
.006\end{array}\right.$ & $\begin{array}{l}2.90 \\
2.00 \\
1.80\end{array}$ & & & & 1.0 & $\begin{array}{l}.002 \\
.004 \\
.006\end{array}$ & $\begin{array}{l}3.0 \\
2.2 \\
1.8\end{array}$ & $\begin{array}{r}1.04 \\
\end{array}$ & $\begin{array}{l}.002 \\
.004 \\
.006\end{array}$ & $\begin{array}{l}3.3 \\
2.2 \\
1.8\end{array}$ \\
\hline .568 & $\left\{\begin{array}{l}.002 \\
.004 \\
.006\end{array}\right.$ & $\begin{array}{l}2.40 \\
1.80\end{array}$ & & & & 2.0 & $\begin{array}{l}.002 \\
.004 \\
.006\end{array}$ & $\begin{array}{l}3.0 \\
2.3 \\
1.8\end{array}$ & & & \\
\hline
\end{tabular}

$\checkmark$ It is to be emphasized that the data in figure 13 do not provide information concerning the mechanism for the formation of maxima. 
of this theory and the kinetics of the adsorptive process, the concentration of suppresser required to give a minimum coverage of the drop should, for a given size of drop, be an exponential function of the drop-time. The dependence of this function on the size of drops has not been fully investigated. However, preliminary experiments with a capillary producing drops of approximately $41 \mathrm{mg}$ indicate a significant dependence. This behavior is now under study.

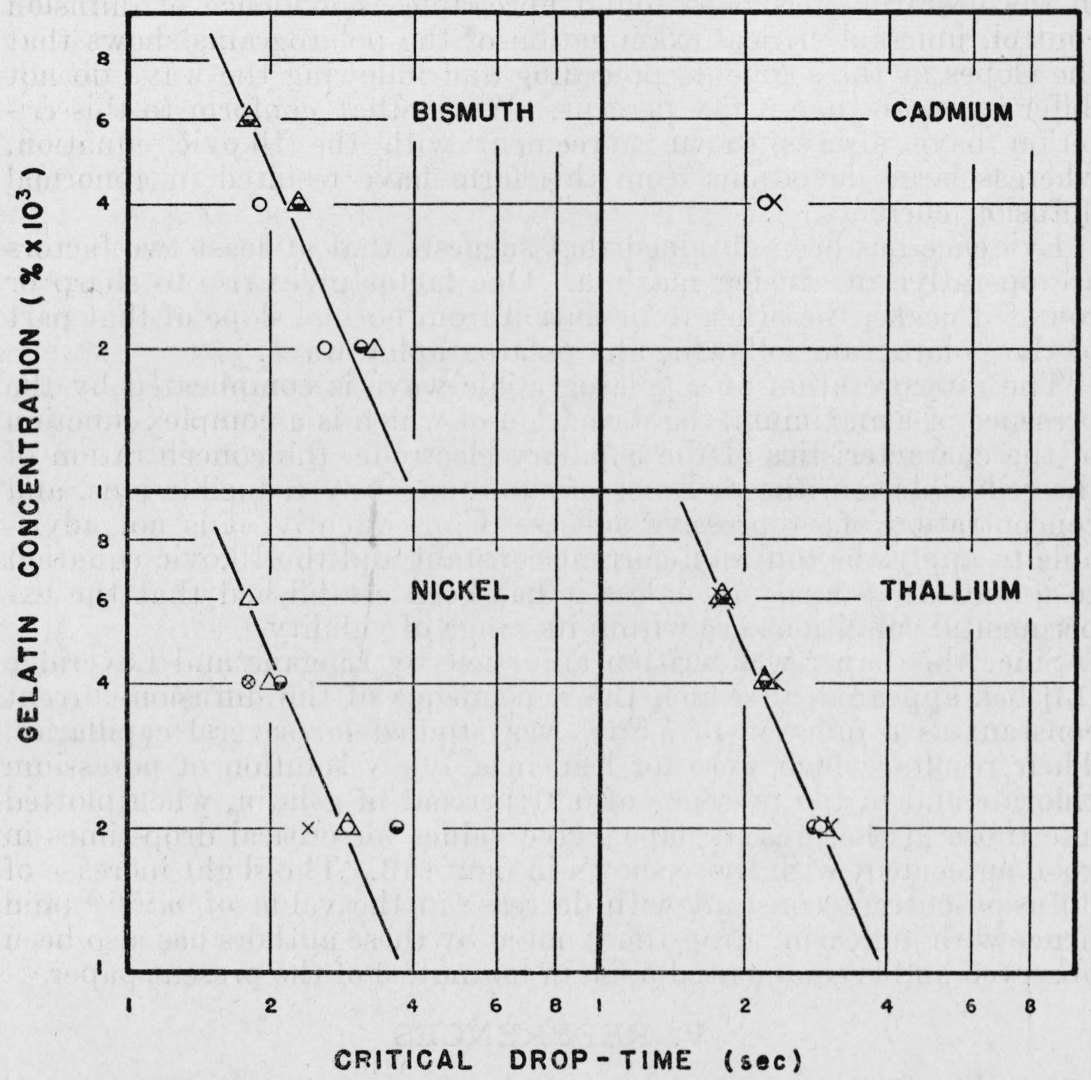

FigURE 13.-Effect of gelatin on critical drop-times for several reducible ions.

Each section of the figure is a logarithmic plot of the corresponding data of table 3. A given symbol in a plot represents a fixed concentration. There is no necessary correspondence between the same symbol used in different plots.

\section{CONCLUSIONS}

One of the important conclusions to be drawn from this research is that gelatin (or some other suppresser) is necessary to obtain agreement with the Ilkovič equation over a considerable range of droptimes for capillaries giving drops in the range 6 to $9 \mathrm{mg}$. The need of a suppresser increases with the dilution of reducible ion and is in all cases most acute for drop-times less than 3 seconds.

The concentration of gelatin required to effect diffusion control over a given drop-time interval is, for a given capillary, practically independent of the nature and concentration of the reducible ion. The effect of an excess of suppresser over that required to insure a con- 
stant value of $I_{D}$ is significant only at high dilutions of the reducible ion.

A linear relation between the logarithm of the critical drop-time and logarithm of the gelatin concentration has been found. This relation has been shown to be independent of the nature of the reducible ion, its concentration, and the supporting electrolyte.

The occurrence of "well-defined" waves so frequently mentioned in the literature has been found unreliable as evidence of diffusion control, unless a critical examination of the polarograms shows that the slopes of the segments preceding and following the wave do not differ by more than a few percent. Waves that conform to this criterion have always shown agreement with the Ilkovic equation, whereas large deviations from this form have resulted in abnormal diffusion currents.

Evidence has been obtained that suggests that at least two factors are operative in causing maxima. One factor gives rise to sharp or rounded peaks, the other to deviation from normal slope of that part of the polarogram following the polarographic wave.

The interpretation of a polarographic wave is complicated by the presence of a maximum, the formation of which is a complex function of the characteristics of the capillary electrode, the concentration of the reducible ion, the presence of simultaneously reducible ions, and concentration of suppressive agents. Consequently, it is not advisable to apply the diffusion-current constant and the Ilkovič equation to quantitative analyses unless it has been established that the experimental conditions are within its range of validity.

Since this paper was written an article by Lingane and Loveridge [13] has appeared, in which the dependence of the diffusion-current constant as a function of $m^{2 / 3} t^{1 / 6}$ was studied for several capillaries. Their results, which were for lead in a $1.0-N$ solution of potassium chloride and in the presence of 0.01 percent of gelatin, when plotted like those in the present paper, give values for critical drop-times in good agreement with those shown in figure 13. The slight increase of diffusion-current constant with decrease in the value of $m^{2 / 3} t^{1 / 6}$ (and hence with increasing drop-time) noted by these authors has also been observed and is commented upon in footnote 3 of the present paper.

\section{REFERENCES}

[1] D. Ilkovič, Collection Czechoslov. Chem. Commun. 6, 498 (1934).

[2] J. J. Lingane, Ind. Eng. Chem., Anal. Ed. 15, 583 (1943).

[3] J. Maas, Collection Czechoslov. Chem. Commun. 19, 42 (1938); I. M. Kolthoff and J. J. Lingane, Chem. Rev. 24, 1 (1939); J. J. Lingane and I. M. Kolthoff, J. Am. Chem. Soc. 61, 825 (1939).

[4] I. M. Kolthoff and J. J. Lingane, Polarography, p. 121, (Interscience Publishers, Inc., New York, N. Y. 1941).

[5] H. Matheson, H. S. Isbell, and E. R. Smith, J. Research NBS 28, 95 (1942) RP1448.

[6] J. J. Lingane, Ind. Eng. Chem., Anal. Ed. 14, 655 (1942).

[7] J. Heyrovsky, Actualités Scientifiques et Industrielles, No. 90 (Paris, 1934).

[8] D. Ilkovič, Collection Czechoslov. Chem. Commun. 8, 13 (1936).

[9] H. J. Antweiler, Z. Elektrochem. 43, 596 (1937); 44, 719, 831, 888 (1938).

[10] Reference 4, p. 269.

[11] O. H. Müller, J. Am. Chem. Soc. 66, 1019 (1944); J. Chem. Education 18, $172(1941)$; J. J. Lingane and I. M. Kolthoff, J. Am. Chem. Soc. 61, 825 (1939) ; J. J. Lingane, Ind. Eng. Chem., Anal. Ed. 15, 583 (1943).

[12] Reference 4, p. 68.

[13] J. J. Lingane and B. A. Loveridge, J. Am. Chem. Soc. 66, 1425 (1944).

Washington, October 20, 1944. 